\title{
Visual metaphorization models in PSA discourse
}

\author{
Marina V. Terskikh
}

DOI: 10.18355/XL.2018.11.02.07

\begin{abstract}
Nowadays we can see that a traditional verbal metaphor is giving its way to more elaborate and complex type - the polycode metaphor. Thus it becomes vital to research such metaphorical structures, where the transfer is performed using an iconic semiotic system and by correlation of visual metaphor with a verbal one. This transfer of the verbal code into the code of images is deemed to have a great persuasive potential essential for PSA's effectiveness. It means that all advantages of metaphoric "packing" of the information can be actualized by the verbal code sufficiently enhanced by the visual code.
\end{abstract}

Key words: visual metaphor, polycode text, PSA discourse, metaphorical modeling, content analysis

The current research is a continuation of works [Terskikh, 2012, Terskikh, Pavchun, 2014] focusing on the specificity of polycode metaphorization in public state announcement (PSA) texts.

\section{Introduction}

In the modern times, it becomes necessary to study metaphorical transfers performed by using an iconic semiotic system, including the interaction of visual metaphors with verbal semiotic system and correlation of verbal and visual metaphors. Thus, this transfer of verbal code to the system of images becomes a tool with high impact potential. All advantages of metaphorical "packing" of information by means of verbal code can be enhanced by the advantages of visual signs.

Modern media texts are more and more often encoded by different types of signs - verbal and visual - creating semantic and functional entities, which exert a complex influence upon the addressee. Modern scientists use different terms to describe this linguo-visual phenomena, for example, creolized text, polycode text, hybrid text, bimedial (polymedia, multimedia) text, supertext, communicate. They are all talking about one type of texts "consisting of two non-homogenous parts: verbal and non-verbal, belonging to other semiotic systems, excluding natural language" [Sorokin, Tarasov, 1990: 180].

Logocentric approach to the text, which was mentioned by German linguist $\mathrm{H}$. Stöckl ("Linguistics' logocentric pride that recognizes priority of language, and particularly written language as a cultural achievement, has led to the situation, when material image is considered to be a source of the second sort" [Stöckl, cited by Chernuyavskaya, 2009: 88]) has been gradually changing towards research interests connected with the specificity of different codes' interaction within communicative entity of the text. Creolization (polycode nature of texts) as an important tool of media communication was the main domain of interest in the works of Yu.A. Sorokin, E.F. Tarasov [Sorokin, Tarasov, 1990], V.E. Chernuyavskaya [Chernuyavskaya, 2009], I. V. Vashunina [Vashunina, 2007], M.B. Voroshilova [Voroshilova, 2009], L.I. Grishaeva [Grishaeva, 2003], O.A. Korda [Korda, 2013], etc.

Non-verbal means of communication become one of the most effective means of persuasion; they no longer act as a subordinate secondary source of information or some kind of manipulative tool compared to verbal elements. Advertising professionals argue that it is a visual component, which has the highest pragmatic and semantic potential, compared to words. That is why the bulk of advertisements base 
upon visual metaphors constructed as reconciliations of two visual images generating some new meaning.

The aim of the present research is to understand and describe specificity of visual metaphorical modeling in the PSA (public state announcement) texts, as well as the interaction of visual and verbal metaphors.

\section{Role of a metaphor in advertising discourse}

Metaphors become especially handy in those types of discourse that require laconism combined with a high impact potential [Budaev, 2017; Ivanovic, 2017; Hampl, 2012]. Metaphors are very "compact", so they are easily introduced into an advertising text. They help to convey a larger amount of information using less amount of words and visual components (in case of using a visual metaphor). "The metaphor is laconic. It easily fits the "tightness of a poetic line" (Yu.N. Tynyanov). It doesn't need any explanations or grounds", says N. D. Arutyunova [Arutyunova, 1999: 354].

If we paraphrase the words of Yu.N. Tynyanov, we can claim that metaphors are very "compact", so they are easily introduced into an advertising text. They help to convey a larger amount of information using less amount of words and visual components (in case of using a visual metaphor).

There are many advantages connected with the transfer of such "packed" information. The metaphor is one of the most effective means of conveying necessary information into the recipient's consciousness, therefore providing less critical comprehension of the information conveyed. N.D. Arutyunova also mentions that metaphor avoids any "explanations or grounds," that is why this transfer of certain qualities of the metaphorizing source to the object of interest becomes an effective cognitive procedure; the recipient is more likely to believe the information seasoned with the metaphor.

There is no comparative link in the metaphorical transfer, so the recipient can ignore the very base for comparison. The conclusion is made not by an addressee, but by the addresser who uses metaphor as a semantically charged cognitive tool with an implicit information potential. This is the second advantage of the metaphorical transfer of advertising discourse. Addressee takes part in some kind of an intellectual game, as he must interpret the information that had been "packed." If the interpretation result is positive (the advertiser's riddle is solved), the addressee usually gets a cognitive and emotional satisfaction. Moreover, these cognitive processes help to anchor some information about the product in the recipient's consciousness.

The creative potential of the metaphor is defined by its very nature because a genuine metaphor is a unique combination of objects, culture-specific concept, etc., with is impossible from the point of view of common logical laws. The metaphor is constructed according to an integration principle in terms or swift drawing together and association of images related to different semantic fields.

Any type of metaphor - verbal or visual - helps to reveal and transfer some individual features of an object, its uniqueness. This can be especially valuable for the product's positioning when goods of one category don't have any distinctive features. In the course of the product's individualizing metaphors work as category mistakes. In other words, the metaphorizing mechanism provides an unconventional submission of information concerning the product of interest or social issue, which is very important for advertising discourse, because the conventional object can be seen from a totally different point of view.

The effectiveness of the metaphor is more intense when there is less in common between the objects under comparison. "The transfer of the name inside natural kinds, meaning inside the stereotypical class, is understood as a metaphor. The metaphor is an eternal source of analogies in the language; it helps to compare the

XLinguae, Volume 11, Issue 2, April 2018, ISSN 1337-8384, eISSN 2453-711X 
incomparable, the elements of different nature..." [Arutyunova, 1999: 367]. Here we face one more advantage of the metaphor for the advertising professional - the author of an advertisement can convey necessary information concerning some abstract characteristics, values, intangible properties, and categories, using the metaphorical transfer.

The major problem of the modern commercial advertising market is that most products inside one product category are identical both concerning their tangible and intangible characteristics. In this case, metaphorization is used as a tool, which helps to objectify and make said characteristics tangible, to present the product in more direct and unconventional form. It also helps to picture common characteristics of products inside the same product category in more apparent, objectified form and to create a basis for products' differentiation. It is metaphorization that allows us to translate separate shades of meaning, add a figurative meaning to the word's semantic structure; it also acts as a source for synonymy.

The goal of any advertisement is to urge its recipient into definite action. Talking about an addressee's goal we get into the PSA's trouble area, meaning the problem of the advertisement's efficiency. In the case of commercial advertizing, we can talk about communicative and economic efficiency (how fast we can remember the text and how the sales rate grows), though in case of PSAs it is getting more complicated. The PSA's efficiency can't be evaluated from the point of view of economic variables. It also has a different level of economic efficiency. PSA's goal is to change the attitudes and life style of people, a process, which is very complicated and time-consuming.

PSA, which aims at the formation of a system of values in the mass consciousness, correction of value-based priorities and guidelines, correction of dangerous and abusing behavior model, needs a non-stereotypical visualization of its objects - social maladies and value paradigms. The PSA's author faces a difficult task to "present an idea, value paradigm, opinion, behavioral model, information concerning an important social issue, in a concise and creative way, which can sensitize the target audience to good deeds" [Chernysheva, 2012: 4]. Visual and verbal metaphors, by all means, help to achieve this goal.

In an image (substantive) metaphor, we find a source of characteristics transferred to an advertised object, though these characteristics lying at the core of this metaphorical transfer are not explicit. The consciousness has a task to select the characteristics of the additional subject, which can be compatible with the nature of the denotatum, which assumes said characteristics. By working with metaphor, (i.e., working with meaning that contradicts logical laws), our consciousness is gradually placing these meanings under logic's command.

Our consciousness has to match the objects, which are contradictory or different from the point of view of logical laws. By overcoming that entropy, the consciousness is searching for an attractor - a common feature that may balance this situation and justify the metaphorical comparison. Mental efforts connected with creation and understanding of a metaphor consists in overcoming this incompatibility. Such complicated cognitive operations provide the effect, which A. Baranov calls an effect of "knowledge privatization," consisting in the transfer of information concerning the properties of an advertised object into the recipient's consciousness.

I should say that the process of metaphor decoding is a variable one; metaphor gives a recipient the possibility to implement his or her own individual creative interpretation of the metaphor.

Thus, the advertising professional should define a "conceptualization corridor" of the metaphor by estimating all variants of the suggested image's interpretation. The visual image can act as an eye-stopper, but if the metaphor chosen doesn't help to form the desired image of the object advertised, such a transfer is believed to be ineffectual. The main means of defining this "conceptualization 
corridor" for information delivered with the help of visual metaphorical code may be verbal elements that let us target the recipients' cognitive processes in accordance with the addresser's needs.

In other words, verbal or visual metaphor in commercial and PSA advertising discourse can't be "purposeless," meaning that function of this metaphor is not limited only by attractiveness or artistic value. Effective metaphor in advertising is always an unexpected image that helps to individualize an advertised object in commercial advertising, or to influence recipient's feelings and emotions, sensitize to actions by representing social norms and values by means of the PSAs.

The visual metaphor also includes an additional creative component - an original way of translation of verbal code into a visual one.

As any creative phenomenon, metaphor tends to lose its brightness and originality in the course of time. It may fade away, especially when it is deliberately repeated in advertising discourse's texts. Visualization mechanism helps us to re-use this trait metaphorical transfer.

In this case, the creative element is provided by some unconventional design embodiment. Thus, we can suppose that both visual metaphor, based upon the conventional metaphorical model, and a visual metaphor, based upon some original idea of comparing the objects of different taxonomic categories, can successfully work in advertising text.

The metaphor is of interest for advertising professionals because it allows correlating objects that belong to different areas by breaking semantic and logic barriers that let us continuously vary forms of metaphorical transfer.

Creativity is some sort of "complication." Thus, the metaphor "complicates" understanding. After some unique metaphorical expression people usually expect a question concerning the meaning of the transfer. We should understand that metaphor as a creative mechanism in literary discourse and metaphor as a creative mechanism in advertising become different categories. Poets and writers may leave it up to the reader to decide what the metaphor used meant. Moreover, the authors of literary works often follow the rule, formulated by a great Russian poet Marina Tsvetaeva as follows: "Never make it easier for the reader. Let him think". [Tsvetaeva, cit. ex Kushner, 1991: 87]. The function of the metaphor in a literary text is to evoke images and individualize object, not to convey information" [Arutyunova, 1999: 367].

In the advertising discourse, the metaphor has to reach other goals as well, to transmit information, which is important from the copywriter's point of view. It is a critical distinction between a metaphor in the literary text and a metaphor in advertising. Metaphor as imagery can be a goal itself, it shapes an image, and the reader is to interpret it himself. Metaphor, being a creative element of the advertisement, should help to reach the ultimate goal of the advertising text. That is why endless variations of image interpretation will lead to its blurring and poor positioning.

Thus, creativity is seen both as an artistic activity (including an innovation component), and as the effectiveness of creative tool used.

Therefore, taking into consideration specificity of the advertising discourse, the copywriter has to use any codes to predetermine invariant interpretation of the image used.

The main means of defining this "conceptualization corridor" for information delivered with the help of visual metaphorical code may be verbal elements that let us target the recipients' cognitive processes in accordance with the addresser's needs.

During pretesting period, the copywriter must study all decoding mechanisms of the metaphorical image transferred in the advertisement. It is a verbal 
component of the message that becomes a key to that meaning of the metaphor, which is important for the advertising professional.

"Both in creative language and in the process of cognition, the objects of the world can't be separated from the reserve of information, concerning these objects (no matter whether they are true or false)" [Arutyunova, 1999: 369]. This thought can also be applied to the visual metaphor used in advertising. Moreover, it is important to choose the most evident characteristic of the source for metaphorical transfer, because here we talk about a distant discourse, which is focused on wide-scale and disseminated addressees. In other words, it is more effective to choose the so-called reference carriers of qualities and characteristics, used as an additional subject in the course of visual metaphor's creation. In this case, the consciousness of the recipient is more likely to follow the conceptualization corridor, set by the addresser.

Therefore, taking into consideration all advantages of the metaphor, we should understand that in the case of advertising communication it must be a result of some creative activity different from the pure artistic creativity.

I believe that verbal metaphor assumes larger recipient's interpretation freedom: he or she may picture in the consciousness the source of the metaphor according to his or her own perception of the object. Thus, in case of visual metaphor perception, the addressee has to follow the image, introduced by the designer. This is a "conceptualization corridor" we have mentioned earlier; the author of the advertisement can highlight, hyperbolize the most important characteristics of the object under comparison; that helps to create the desired image.

Slogan - a key word of an advertising text - becomes a verbal constant of the advertising message, which has the most difficult task to draw attention to the whole advertising campaign. "Research of slogans' effectiveness show that consumers comprehend information much better when the text formula of the slogan is a complex one: informative + metaphorical. Also, it mustn't be some strict information, introduced directly and rationally, but "soft" creation of awareness, which is always easier due to the usage of unusual metaphors" [Yurieva, 2015: 60].

The metaphor used in a slogan lets the author make the text more lively and expressive, as well as catch the addressee's attention (so-called attractive and aesthetic functions). One of the main characteristics of the metaphor is a principle of language economy. It becomes even more important, taking into consideration the peculiarities of the advertising discourse. Here the metaphor meets all requirements of the advertising text, for which the language compression becomes the main principle of the text creation: laconic statement includes an informative and deep meaning.

Therefore the metaphor executes cognitive and pragmatic functions; it is a powerful tool used to influence the addressee's consciousness. One of the ideas of cognitive metaphor theory is that the metaphor has a very important cognitive function of gaining new knowledge. As a result, it influences decision-making processes. "According to modern understanding, decision-making process includes the following phases: 1) comprehension of the problematic situation; 2) searching for alternative ways of the problematic situation's solving; 3) evaluation of these alternative ways; 4) choice of one of the ways (making the decision). The metaphor may influence any phase of this decision-making process, but it is especially useful at the phase of alternatives' searching" [Baranov, 2014: 19].

This fact is crucial for the PSA discourse because its effectiveness is defined by the decisions made by the recipient, meaning his or her choice of a definite social model. A.N. Baranov argues that "the choice of metaphorical model can impose and form a set of alternative ways of the problematic situation's solving" [Baranov. 2014: 19]. This signifies the importance of research of metaphorical modeling in the PSA area being a persuasive discourse.

Very often, a verbal part of the PSA text, particularly slogan, is based upon metaphorical transfer. 
*Let's throw smoking as far as possible. Tobacco is your enemy.

*Break a cigarette before a cigarette breaks you.

*Zebra is the main horse. Slacken speed at a crossing.

*A man is the nature's child, and its heart is also beating, though it is beating slower and slower...

*A drunk driver is an armed criminal.

Such slogans, for sure, accomplish their main function; however, we need a visual element to make the advertisement work, to evoke emotions of the target audience representatives, and to galvanize them into action. It is not always possible to reflect all phases of decision-making, described by A.N. Baranov, by a laconic verbal element of the text, usually compressed into a slogan. The information presented in a visual form accesses the addressee's consciousness quicker and is captured there much more effectively, motivating the addressee. An interesting visual component makes the brain work and tries to solve the author's riddle while concentrating on the main idea of the message.

Visual metaphors play an important role in the advertising practice. Very often, it is the image that helps to convey meaning, which can be lost in the course of the verbal description, and enhance the text's persuasive potential.

Many research works are connected with studies of metaphoric models' analysis methodology. The most logic and detailed methodology called metaphorical modeling are based on the theory of conceptual metaphor.

The theory of conceptual metaphor roots in understanding the metaphor as a verbal phenomenon that reflects the process of cognition and perception of the world. According to the theory under discussion, metaphorical models constitute a part of the human conceptual system. They are kind of a scheme, according to which a human being thinks and acts. That is why observations of metaphors' functioning become an important source of knowledge about how human consciousness works.

According to A.N. Baranov's descriptive theory of the metaphor, metaphorization process is seen as a reflection of elements from the source domain in the target domain (departure domain and arrival domain respectively). "Metaphorization is based upon interaction of two structures of knowledge: cognitive structure of the source domain and cognitive structure of the target domain. During metaphorization process - metaphorical projection - the source domain structure is cognitively reflected in the target domain structure. Thus the source domain structure is partially recreated in the target domain structure" [Baranov 2014: 12]. Signification descriptors, combined with a common topic, create metaphoric models (M-models). "Each model can be described using a hierarchy of signification descriptors' trees. The main task of metaphorization's description is to define the composition of Mmodels" [Baranov, 2014: 15].

\section{Visual metaphorization models in PSA discourse}

In the course of the research, 130 PSA messages in the form of TV and outdoor advertisements were analyzed. It allowed defining some metaphorical models that function in PSA discourse: anthropomorphic, zoomorphic, phytomorphic and artefactual.

\section{Anthropomorphic metaphor}

The source domain is a human body (its anatomy and physiology).

It is common knowledge that the person reflects the reality in his or her own image. Construction of advertised reality is also performed by comparing some phenomena with a human. Anthropomorphic metaphor in PSA texts is expressed by the metaphorical model "Community / World (particularly phenomena describe in the scope of some social issues) is a human body" (social issues are perceived through the prism of anthropomorphic metaphor), though there exist other variants of this

XLinguae, Volume 11, Issue 2, April 2018, ISSN 1337-8384, eISSN 2453-711X 
metaphorical transfer. Let us research the main frames of this metaphorical model: "Human body," "Diseases."

Frame 1 "Human body" (includes slots: "Parts of the body," "Internal organs," "Blood system," "Physiological actions").

Most of the PSA texts generated by the PETA International organization (People for the Ethical Treatment of Animals) use the metaphorical model "A human being is an animal", because this organization's motto is "animals are not ours to eat, wear, experiment on, use for entertainment, or abuse in any other way (see picture 1).

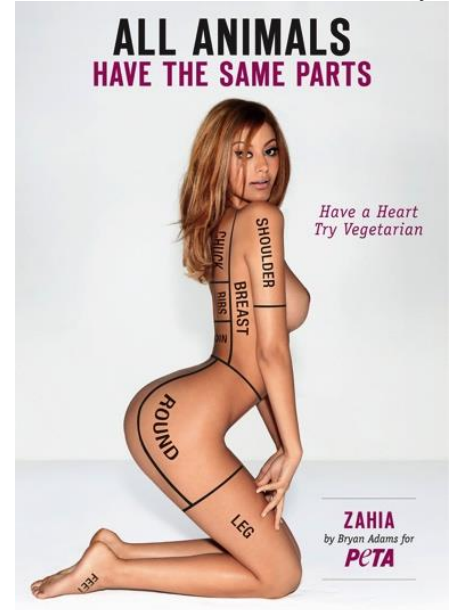

Picture 1

The international Wild World Fund for Nature usually asks the hunters to imagine that the cub of the animal to be killed is a human child. Here is the example of the company "Imagine this is yours" (see picture 2).

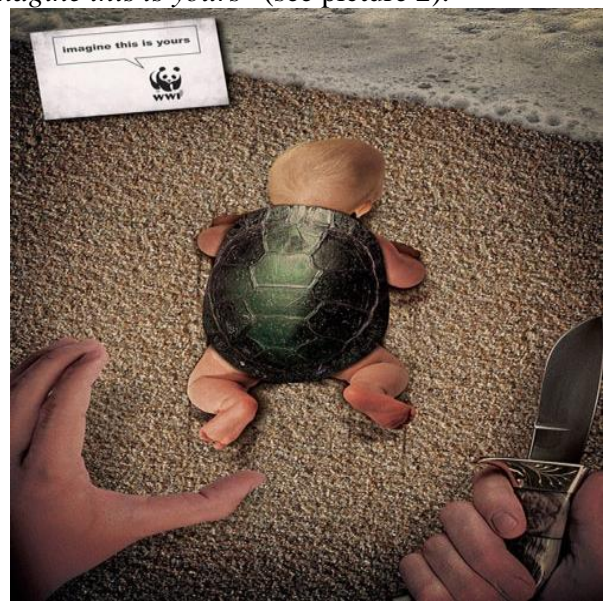

Picture 2

Very often, the authors of PSA messages use metaphorical transfer based on the personification of trees: usually, it's the model "Tree is a human begging for help" (see picture 3). 


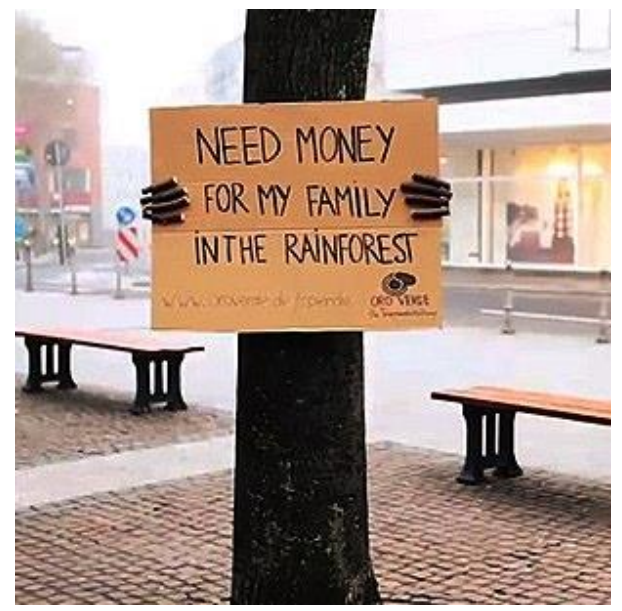

Picture 3

The model "The thing is a human" is also used in the social communication of that kind. For example, in the frameworks of the project "Rubbish has its home" the designers made cans, bottles, etc., look like human being asking people for help (see pictures 4-5).

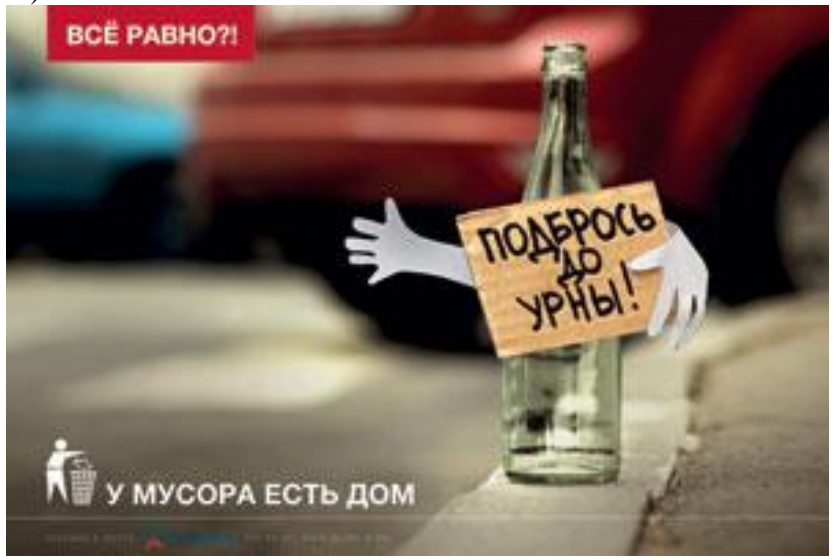

Picture 4

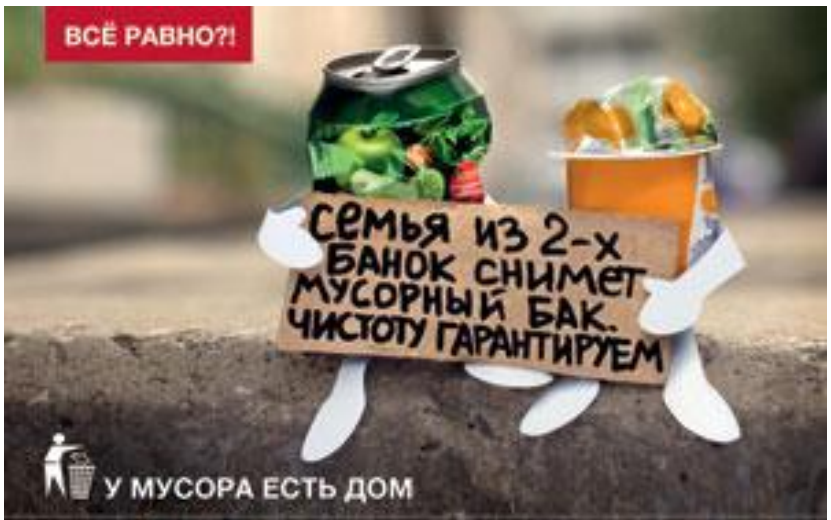

XLinguae, Volume 11, Issue 2, April 2018, ISSN 1337-8384, eISSN 2453-711X 


\section{Picture 5}

\section{Slot 1. Parts of the body}

PSAs often use a metaphorical depiction of parts of the human body. This frame proved to be the most frequent in the model under analysis.

For example in the model "Tree is a human body" the metaphorical transfer can be performed using a synecdoche: "trunk is a leg." Thus the authors visualize trees leaving the city area, which means that the life of humans can also be consequently reduced. The next example pictures the idea that "Humanity and nature are one." It explains the usage of metaphorical models "Trunk of the tree is a human hand" and "Trunk of the tree is a part of the human body" (see picture 6).

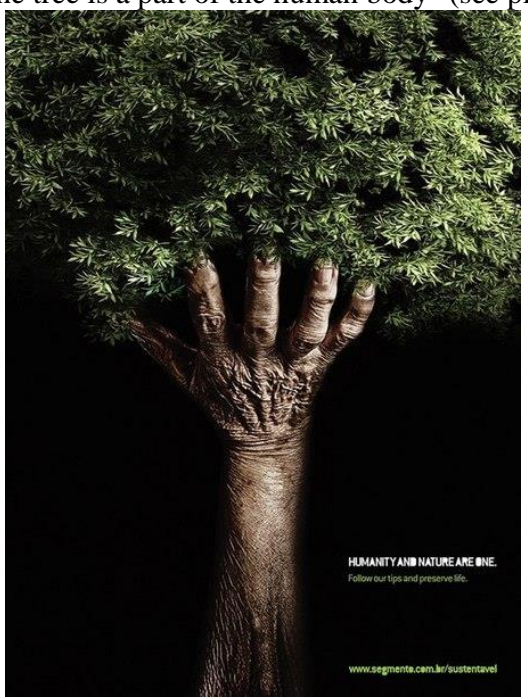

Picture 6

Very often, the authors of PSA messages use the model "Family is a part of the human being," the metaphor is visualized by picturing a family as a part of the human hand (see pictures 7-8).

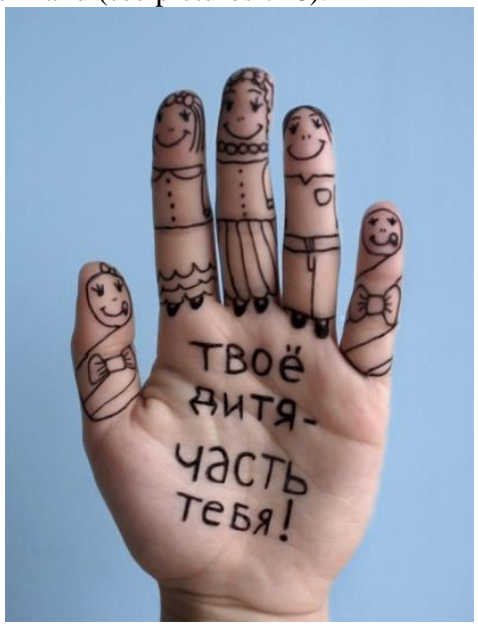

Picture 7

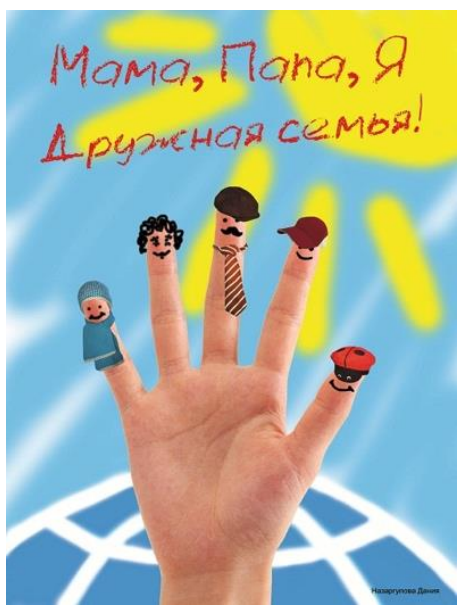

Picture 8

Singapore branch of the SAATCHI \& SAATCHI SINGAPORE agency draws our attention to the problem of verbal violence, showing that words can really 
hurt: verbal violence has the same impact as regular violence (see picture 9).

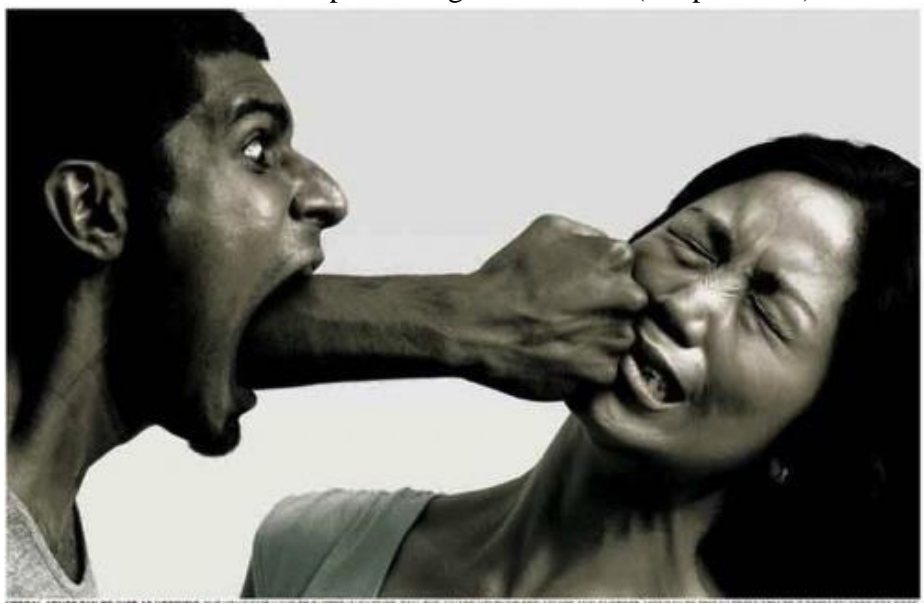

Picture 9

The next example represents the metaphorical perception of the human head as a helmet, meaning that if you do not use your helmet, your head may become one (see picture 10).

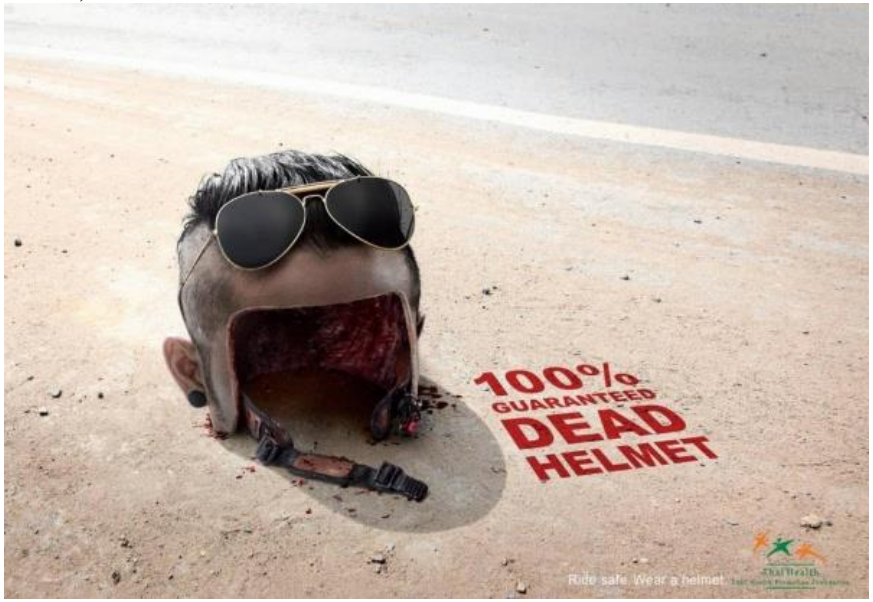

Picture 10

Slot 2. Internal organs (heart, lungs, etc.)

"Forests are the lungs of the planet" is one of the most frequently used metaphorical transfers. This rather stereotypical metaphorical model starts a new life in PSA discourse thanks to the visual component, which gives some variations of the well-known image. Usually, the authors define conceptualization corridor of the visual element by adding a slogan that repeats or elaborates the meaning of the iconic element. "Save rainforests. To feel how important it is, try to stop breathing" (pictures 11-12). 


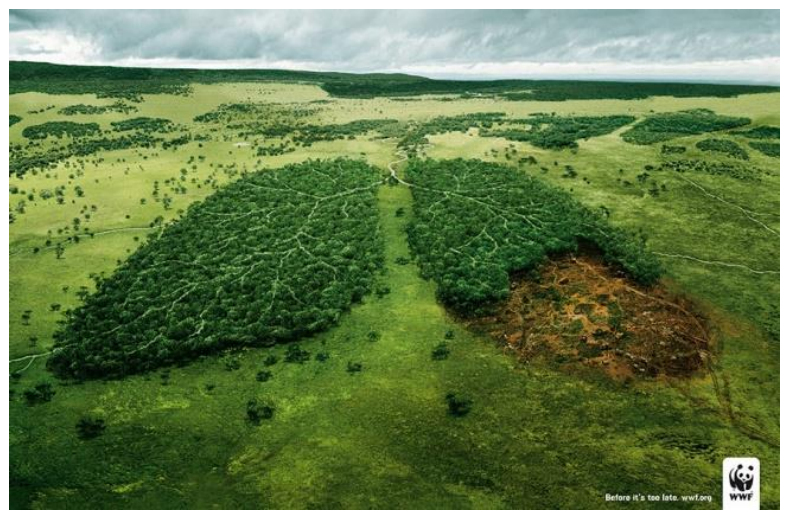

Picture 11

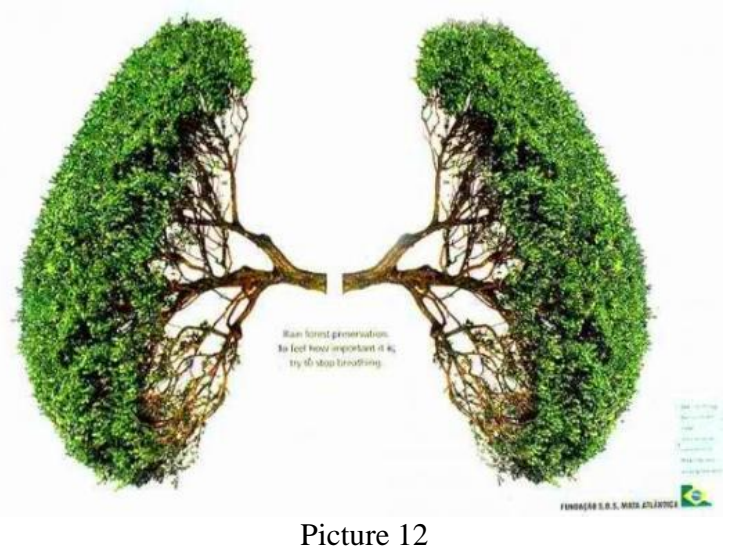

Slot 3. Circulatory system.

There is a quite regular metaphorical transfer "Plants comprise a circulatory system of the planet": by cutting trees, we can kill the planet as well as we can kill a human being by slitting his or her wrists (see picture

13).

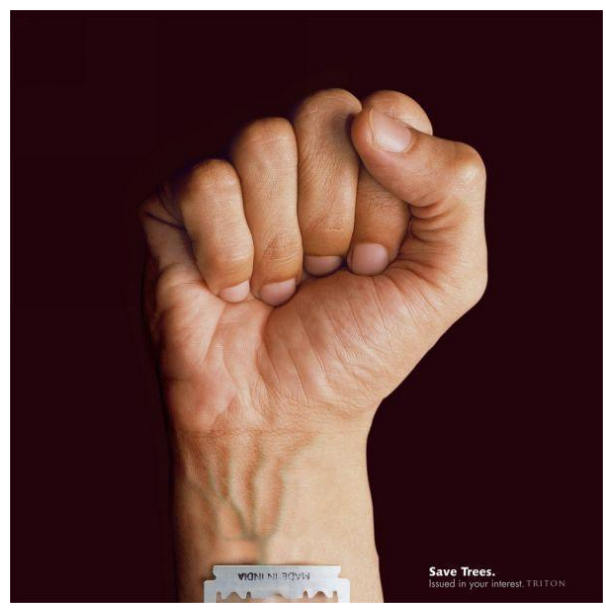




\section{Picture 13}

Slot 4. Physiological actions (birth, death)

Nearly all vicious habits are "packed" by the advertising professionals into the metaphor of death or suicide: "Smoking is death," "Alcohol is death," "Drugs is death" (see pictures 14-15).

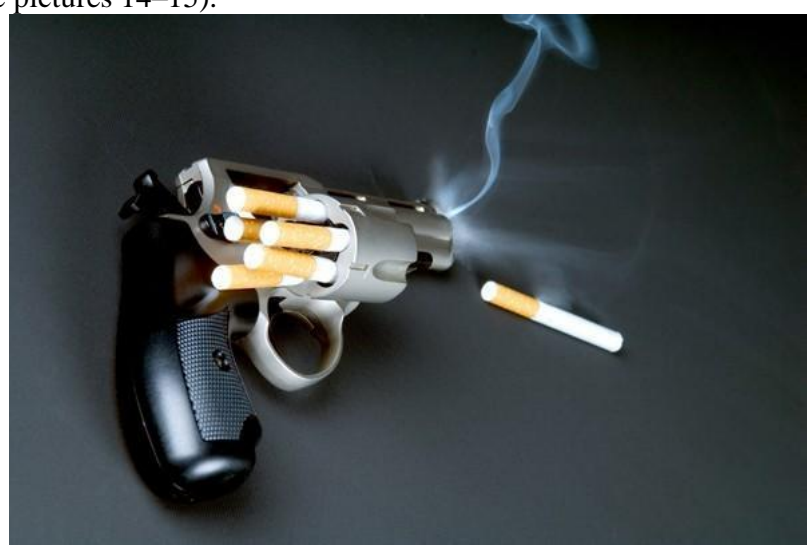

Picture 14

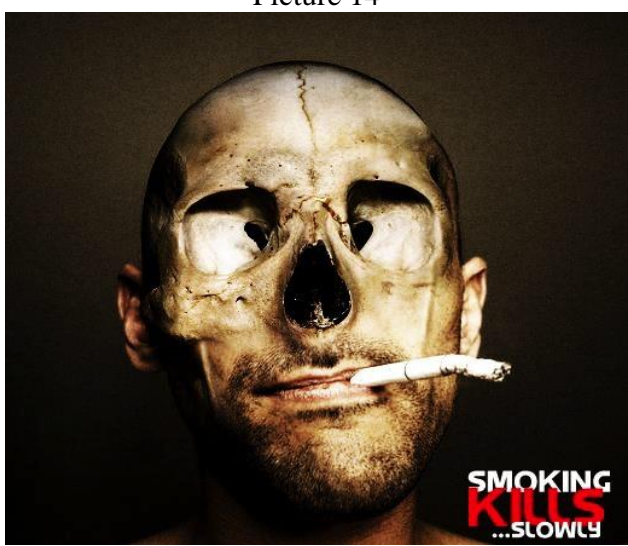

Picture 15

The PSA campaign, connected with donorship, uses the metaphor "Donorship id birth," emphasizing that if you give your organ to another person, you help him or her to be born again. The visual component comprises people as feti, located in the kidneys of other people (see picture 16). 


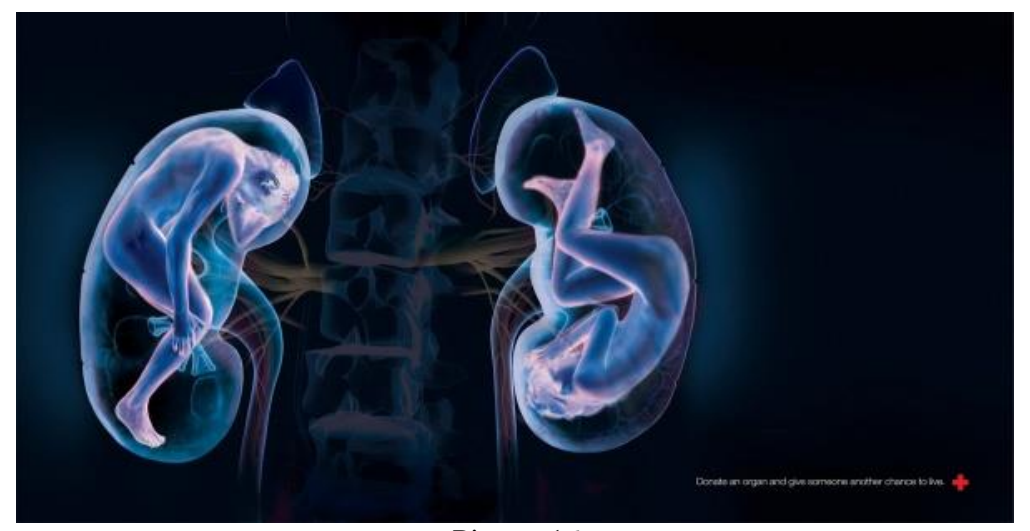

Picture 16

Reckless driving is also very often represented by the visualized metaphor of death (see picture 17-18).

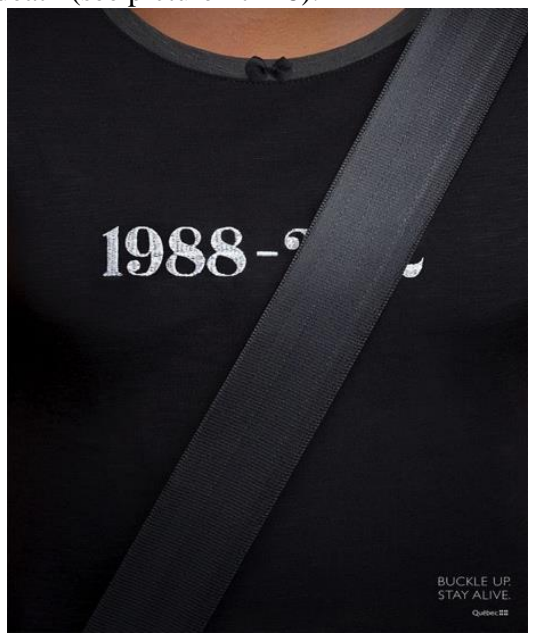

Picture 17

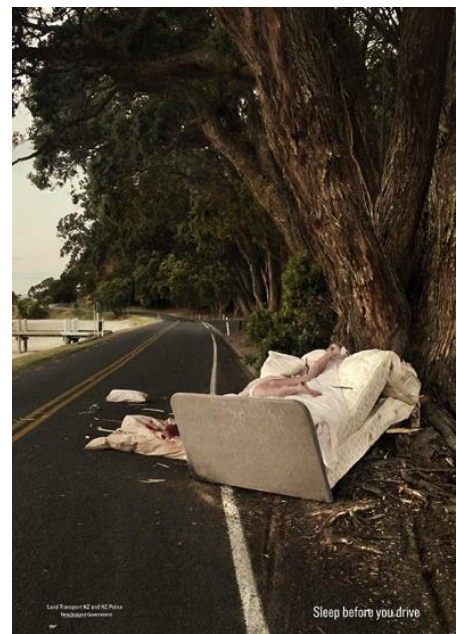

Picture 18

The lack of attention to ecology issues is also often "packed" into the metaphor of death, meaning the death of the human being or other living creatures: «Plastic bags are death," "Trash id death," etc. (see picture 19) 

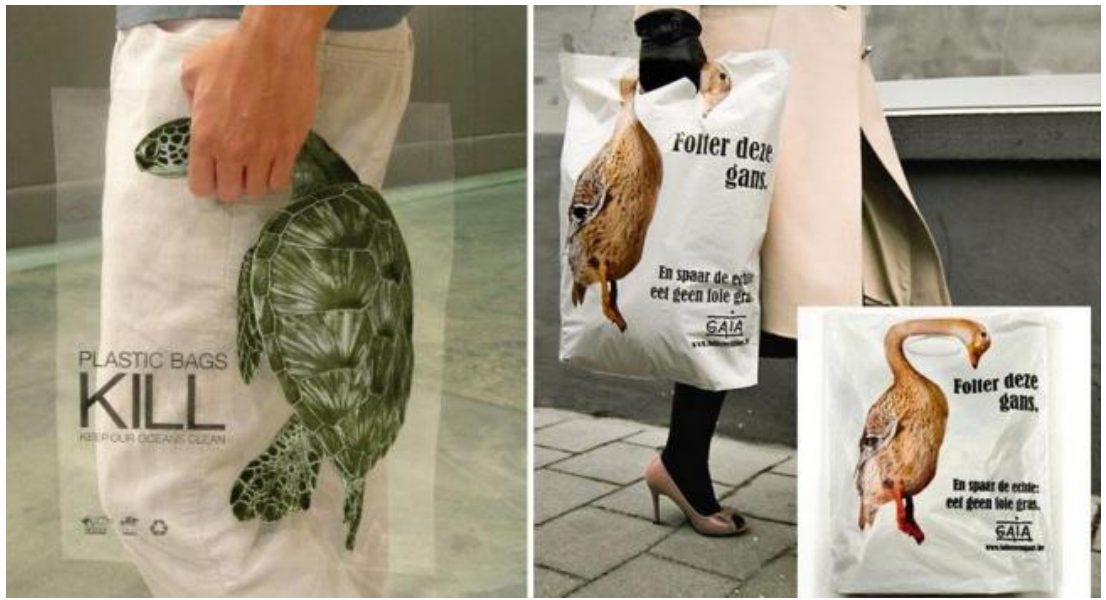

Picture 19

In the posters "If you don't pick it up, they will" you can see dead animals stuffed with trash (see picture 20).

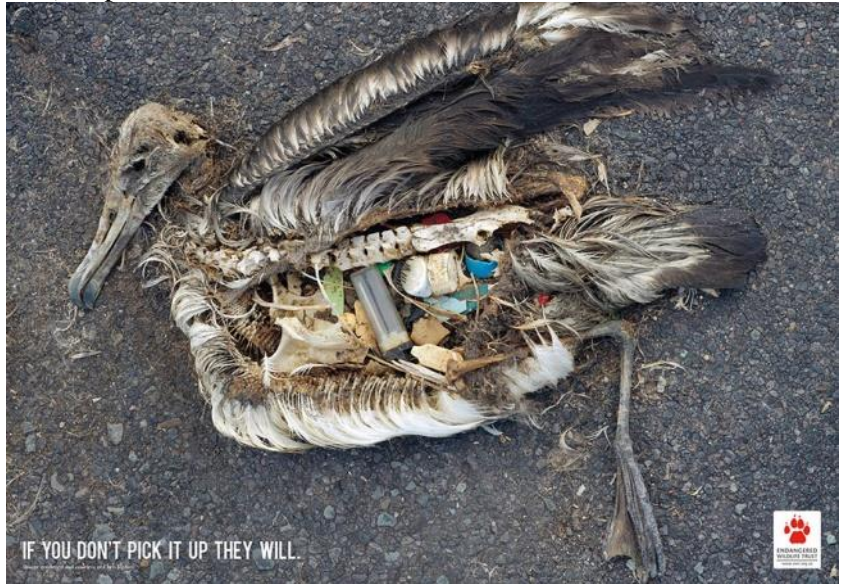

Picture 20

Frame 2. Diseases (slots "Psychical disorders", "Psychical disorders").

The most frequently used model in this frame is "Social Issues = disease."

According to this model, the PSAs often use the images that picture "wounds and diseases" of the society. These metaphors suggest the thought that the society, as well as its separate elements, should be treated. Some of these elements have already died, so waiting the time can lead to some irreversible effects (disability, death, epidemics).

\section{Slot 1. Physical disorders}

Nowadays we are facing a problem of PSA effectiveness because it becomes difficult to attract attention to the definite social problem. To increase the effectiveness of the advertisement its creators usually use the strategy of provoking an agitated state of the addressee resulting in his or her shock state. In the bulk of the PSA messages, the argumentation grounds are based upon pragmatic arguments that appeal to a vast category of harm. Using this type of argumentation we can draw the

XLinguae, Volume 11, Issue 2, April 2018, ISSN 1337-8384, eISSN 2453-711X 
addressee's attention to negative outcomes of some actions (harm connected with smoking, alcohol consumption, drugs, pollution, road accidents, etc.).

As the examples show, the PSAs usually appeal to the necessity of selfprotection, when the author warns the addressee about potential harm to health, social and personal threats, even about the possibility of death. That is why the metaphor of disease becomes a ground for a bulk of PSAs. It warns people of the consequences of harmful habits, road accidents, pollution, etc.

Nearly all PSA messages, connected with anti-smoking campaigns, are built according to the model "Smoking is death," or "Smoking is a disease (lung cancer, erectile dysfunction, emphysema, stroke, etc.) - pictures 21-22.

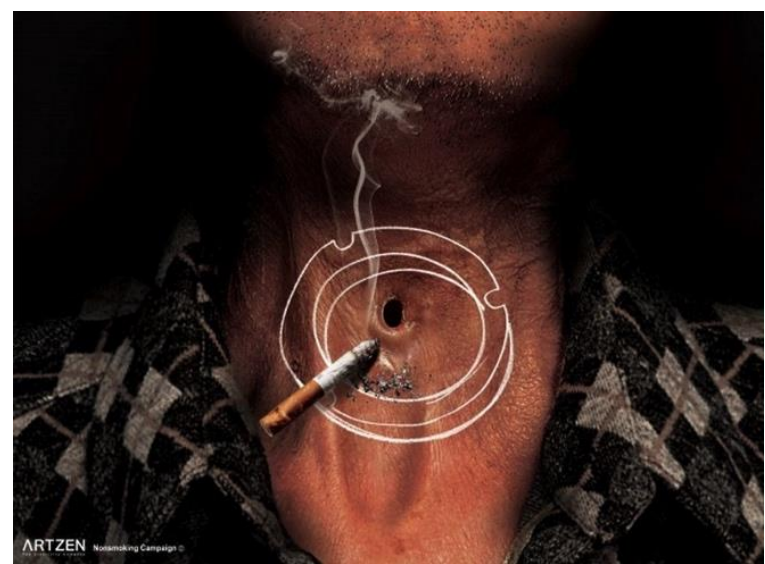

Picture 21

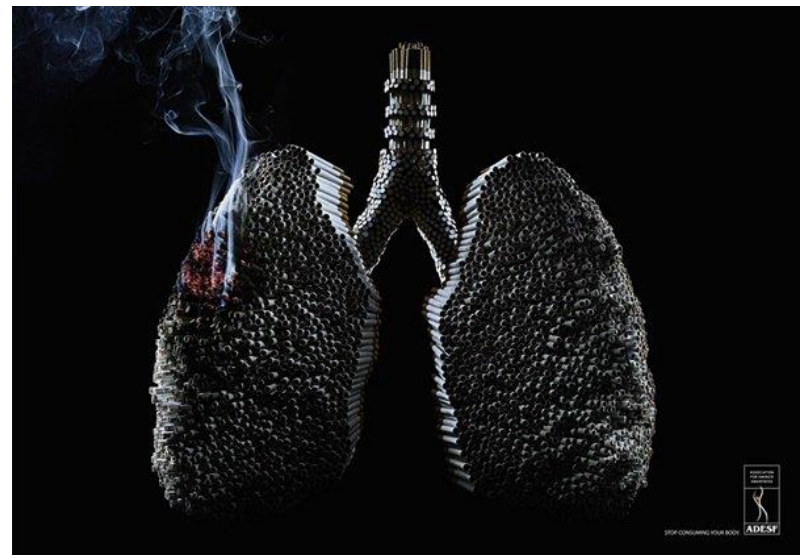

Picture 22

PSA messages often use the phenomenon called metaphtonymy - the interaction of metaphor and metonymy in expressions for linguistic action [Goossens, 1990]. As Beatrice Warren says,"metaphor can be said to involve an element of hypothesis: Life is thought of as if it were a journey. Metonymy, on the other hand, is non-hypothetical... It amounts to a completely factual statement" [Warren, 2006: 15] (compare to G. Barden's words: "metaphorical links are much more in the mind whereas metonymic links are much more a case of reflecting what is objectively in the world" [Barnden, 2010: 8]). 
Thus, the PSA messages that warn people of the consequence of eating a lot of sweets to become a good example of the metaphor of disease combined with metonymy: e.g., "Sweet - diabetes - sphacelation - foot amputation" or "Sweet diabetes - heart disease (see pictures 23-24). PSA texts very often use such metonymic chains that help to enhance the persuasive effect of the message and to present different variants of disease progression.

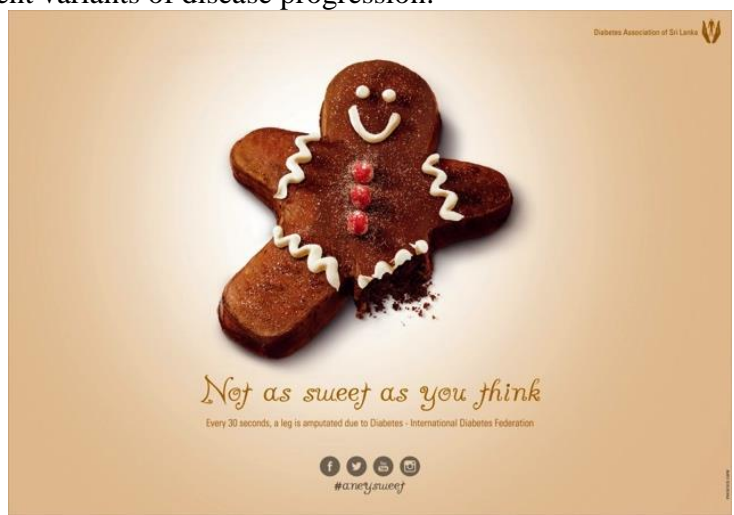

Picture 23

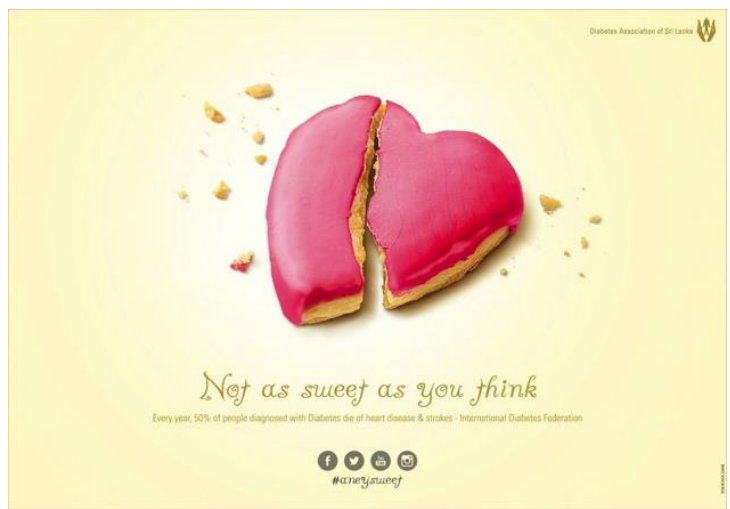

Picture 24

PSA texts usually use verbal and visual elements to add meaning to each other. Thus, a visual metaphor of disease can elaborate in the verbal element, very often it is a presumable outcome of the disease, meaning metaphor of death.

The PSA campaign, connected with diabetes and its consequences, wounds on human bodies are made of sweet things and represent the metaphor of disease, though the slogan of the campaign is "Sweet kills" that represents the metaphor of death (see pictures 25-26). 


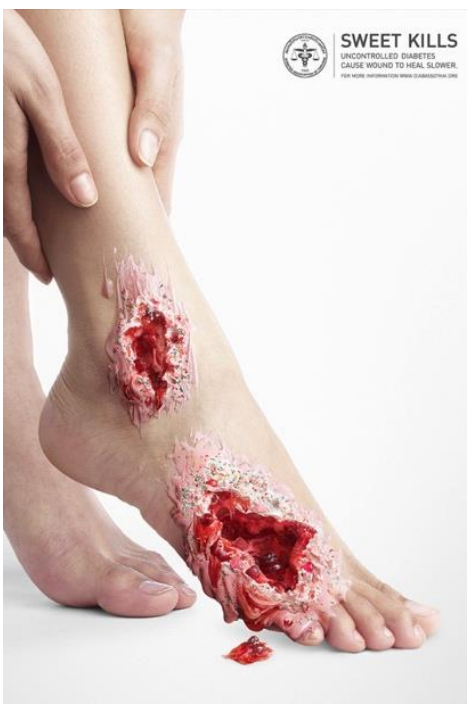

Picture 25

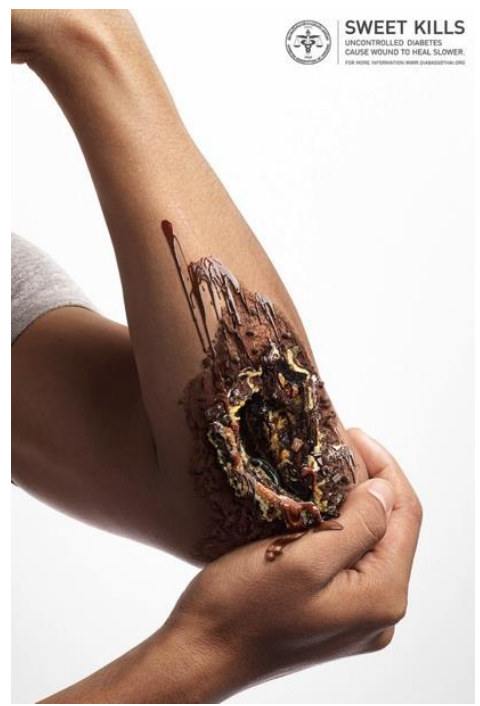

Picture 26

\section{Slot 2. Psychical disorders}

Very often PSA messages are based on the metaphorical transfer, connected not only with diseases but also with psychical disorders, being a problem both for individuals and for society. While smoking is represented in the context of physical diseases, alcohol, and drug addiction, problems of violence and harassment are represented by the metaphors connected with psychical disorders.

Alcohol is often shown as a cause for uncontrolled aggression (see pictures 27-28).

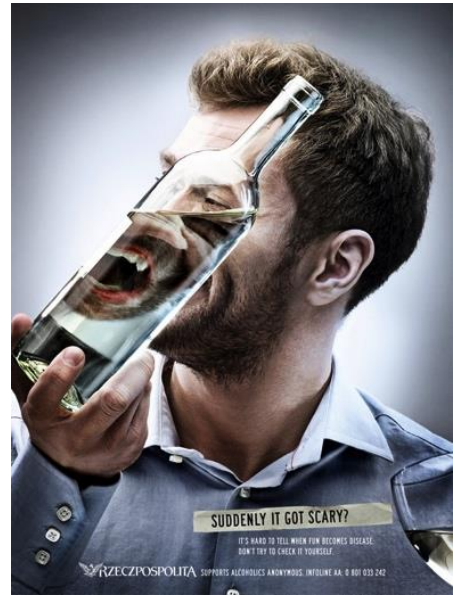

Picture 27

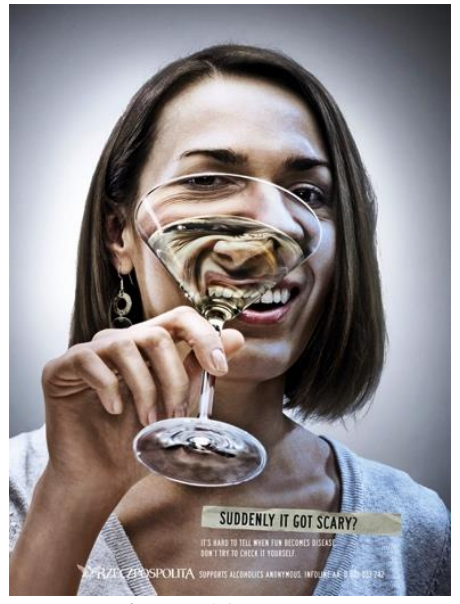

Picture 28

One more cause of a psychical disorder is sexual harassment, particularly regarding harassment of children. The poster of London Children's Charity Fund Barnardo's shows a girl with a face of an elderly woman sitting on a bed. The slogan goes as "Sexual harassment steals children's lives." In this case, a picture of a schoolgirl, who got old before her time, reflects the psychological state of a child, who has no chance to go back to her childhood again (see picture 29). 


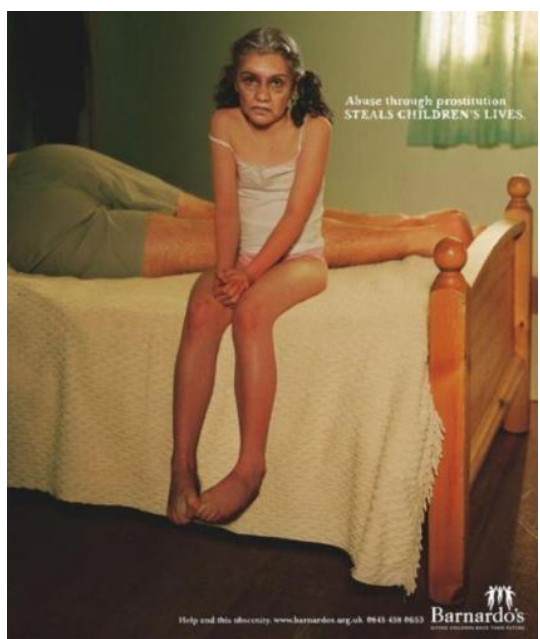

Picture 29

The idea of the following series of PSA posters is that sexual harassment, which people experience as children, never goes away. The posters show elderly people who were sexually harassed as children, and the rapers' hands are still touching their bodies (pictures 30-31).

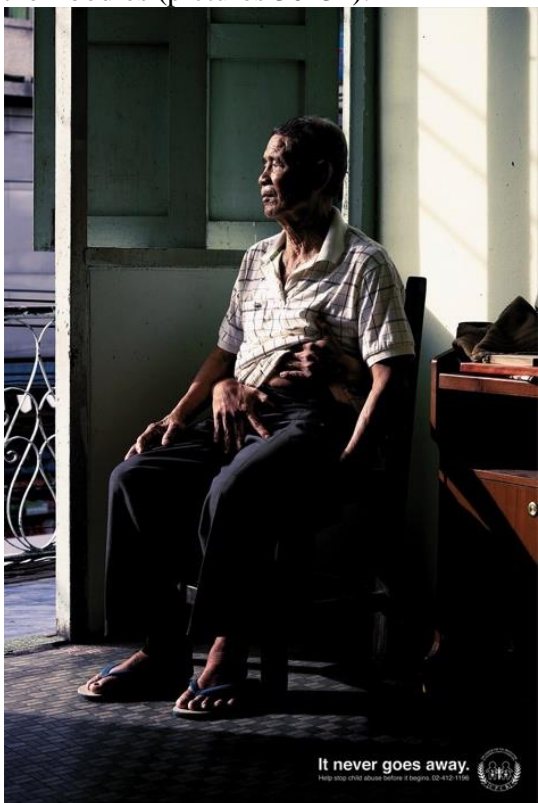

Picture 30

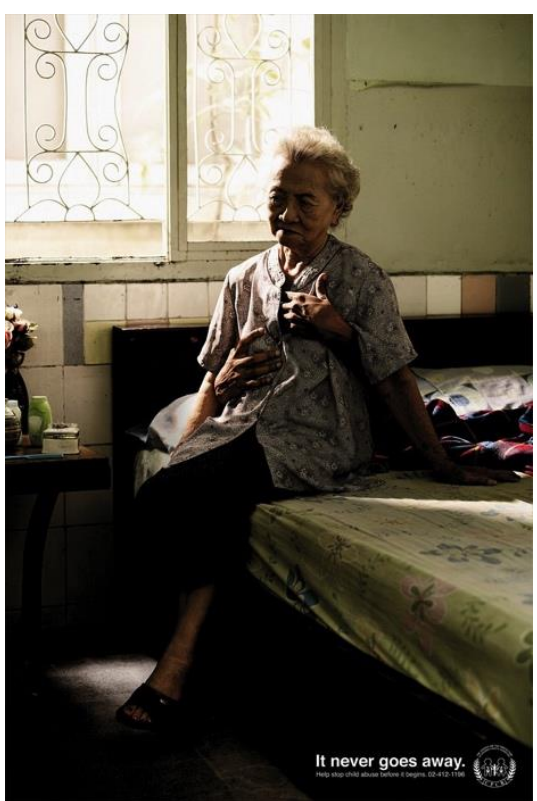

Picture 31

A bulk of PSA messages dealing with domestic violence highlight the fact that children and teenagers, who regularly witness domestic violence, will easily adopt this gender model in future. Thus, the society receives one more violent individual. Very often PSA texts are illustrated by pictures, where we can see frightened and crying children; these visual components are reinforced by the slogans "The only witness won't talk", "Includes scenes, where daddy is beating mummy, because supper was served too late", etc. - pictures 32-33. 


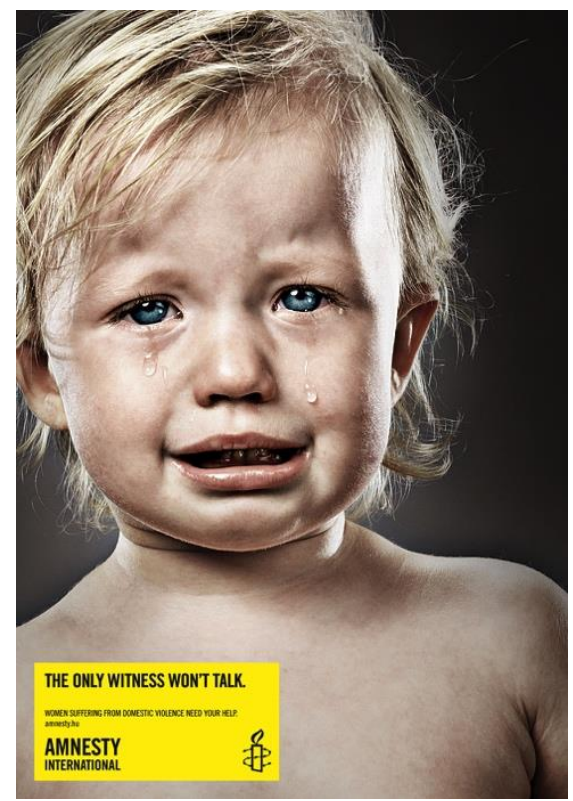

Picture 32

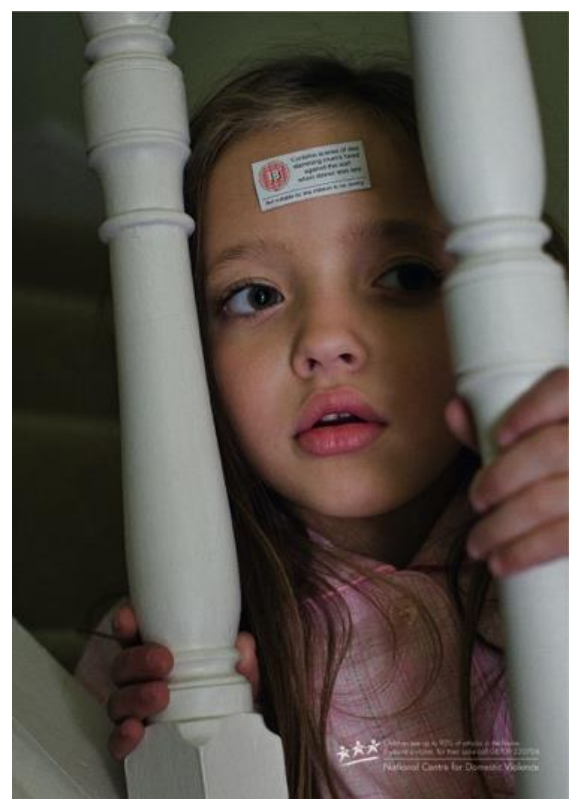

Picture 33

\section{Zoomorphic Metaphor}

A source domain is an animal world.

Frame "A person suffering from social malady = an animal.»

One of the most popular metaphorical models is the zoomorphic metaphor. Its cognitive source is the image of an animal transferred to a human being.

Thus, the model "Person is an animal" is used in a PSA dealing with 
problems of drug addiction. The target audience is teenagers. The teenagers, experimenting with drugs, are shown as rats, slugs, and ants. These anthropomorphic animals are treating each other with toxic substances, such as raticide, insecticide, etc. The slogan of the campaign is "Is it the worst that could happen?" (see pictures 34 35)

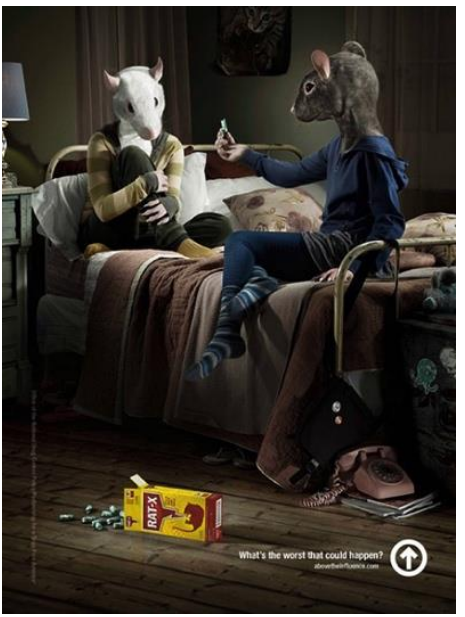

Picture 34

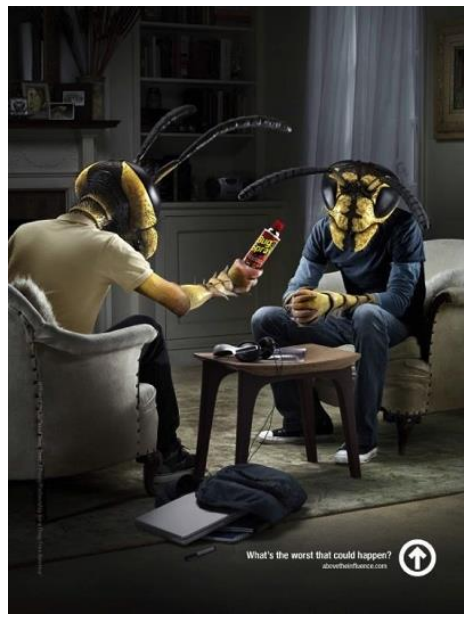

Picture 35

The international Wild World Fund for Nature usually uses anthropomorphic and zoomorphic metaphors to show a tight connection between people and nature, including animals. Slogan: "If they are extinct, we'll be extinct as well. "The image of a man acting as alligator symbolizes the fact that all of us is a part of one big world (see picture 36).

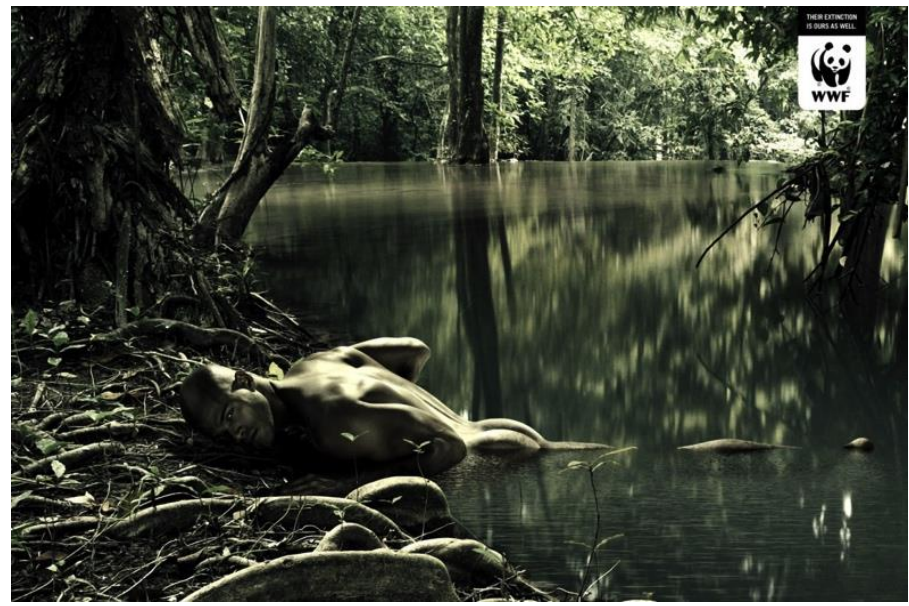

Picture 36

The main slot of this frame is connected with the animals' actions.

PSAs often use the zoomorphic interpretation of actions, which are not typical for mentally sane people.

XLinguae, Volume 11, Issue 2, April 2018, ISSN 1337-8384, eISSN 2453-711X 


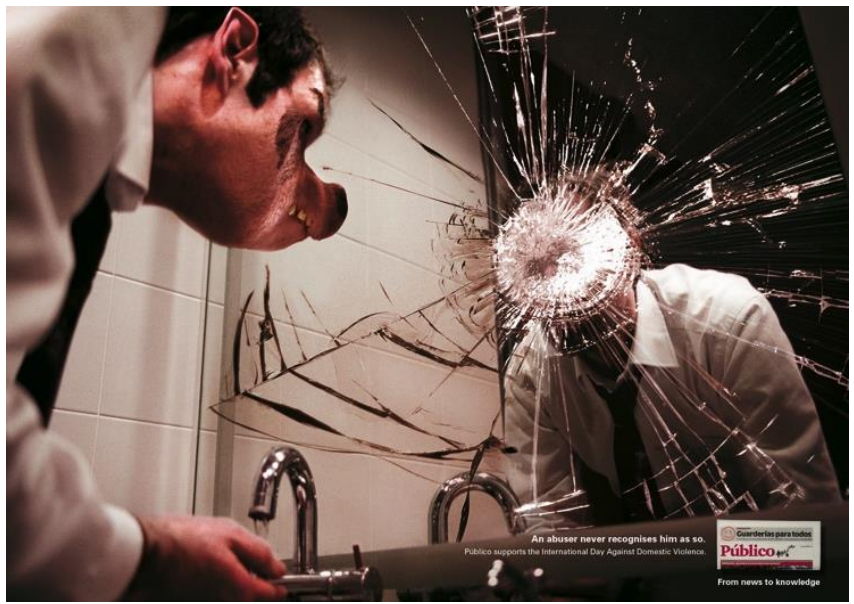

Picture 37

"The offender will never admit he's the one" (a poster for the International day against domestic violence) - picture 37.

In 2015 French transport operator RATP issued a series of posters based on zoomorphic metaphors and showing how some people behave in the public transport (a chicken-girl is talking on her mobile, a bull-man is clearing his way with his horns, a lama-man is spitting on the floor, etc.). The slogan also highlights the images created - "Remain human in public transport" (see pictures 38-39).

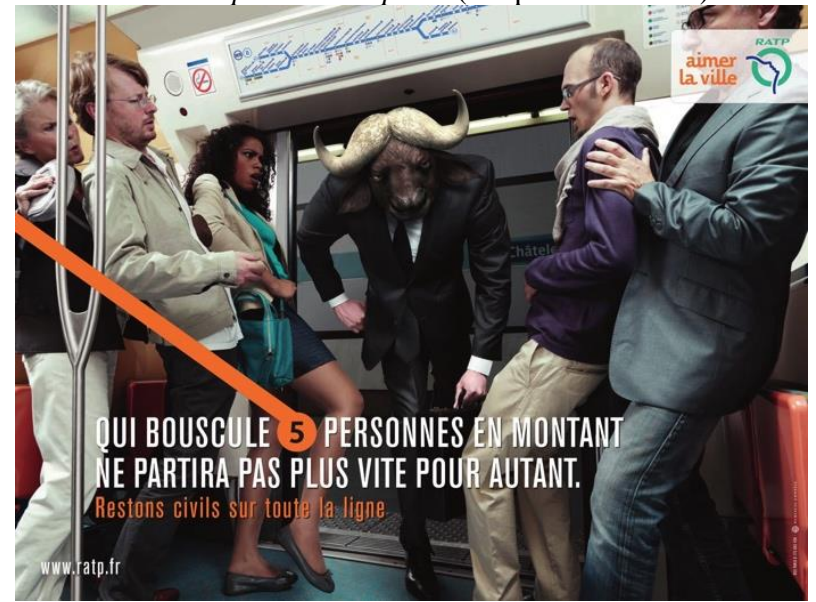

Picture 38 


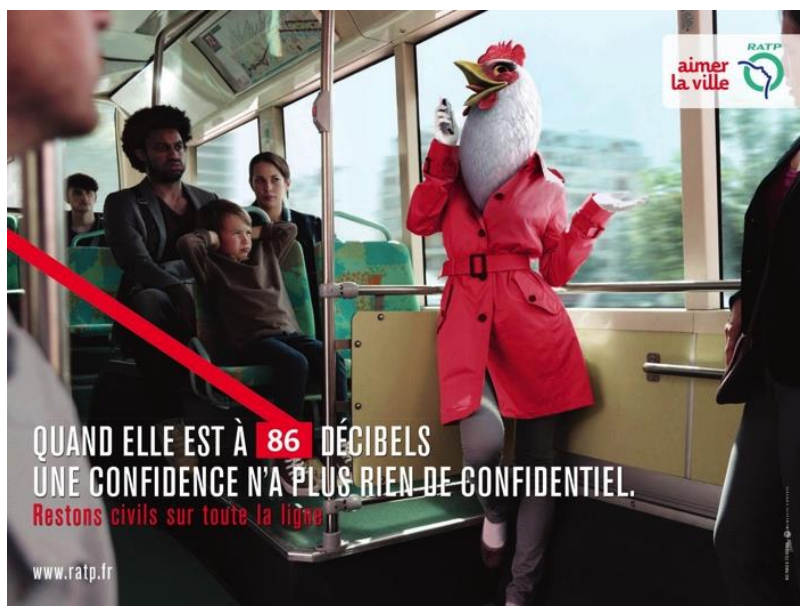

Picture 39

The zoomorphic metaphor is quite often used in PSA texts together with verbal element adding meaning to a visual one that helps to enhance influence upon the target audience.

In 2006 the PSA campaign "Get Unhooked" gained a great public response both in Russia and Great Britain. These texts used a metaphorical transfer "Smoker is a hooked fish" (see pictures 40-41). It was the visual element that enhanced the effect of this PSA.

\section{Phytomorphic Metaphor}

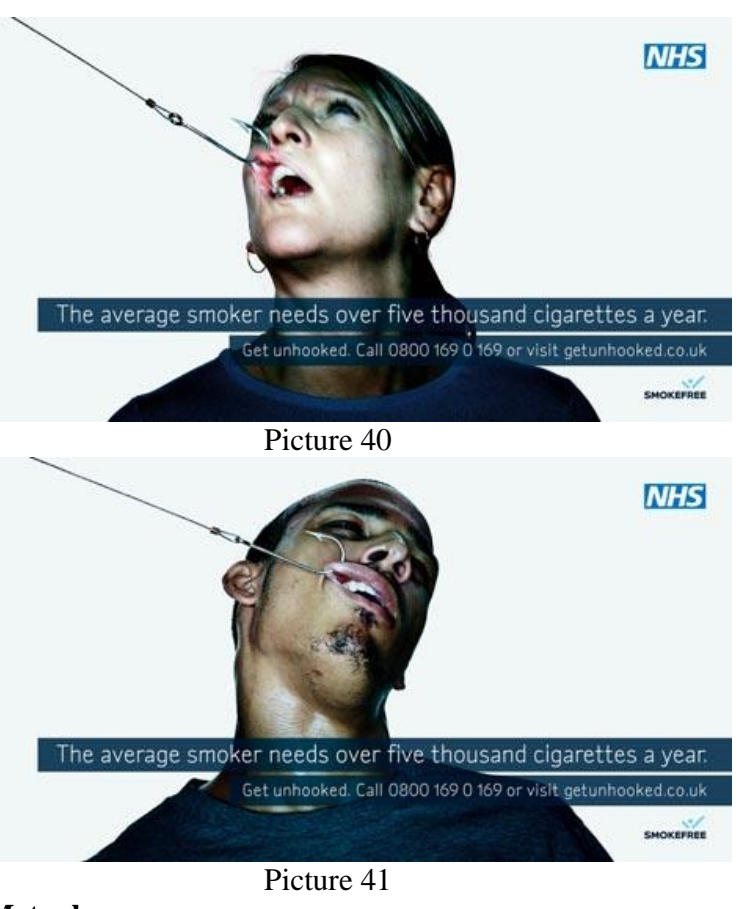

A source domain is a world of plants. 
Very often people compare themselves to the objects around them, including plants. It explains frequent use of one more type of metaphorical transfer characteristic of an individual and his or her state of mind with the help of phytonim.

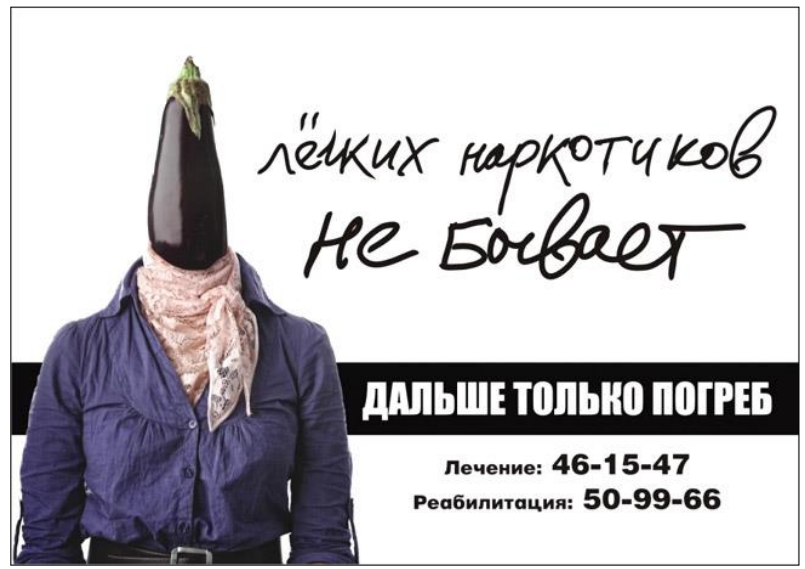

Picture 42

There is an example of the model "Man is a vegetable": "A person who uses drugs is an eggplant." This visual image is enhanced with a slogan: "There are no light drugs, your future is in a vault" (see picture 42).

One more function of the phytomorphic metaphor is to make the message sound more aesthetic. The advertizing agency CCZ WOW from Brazil issued a series of posters, where they "packed" the problem of wild fires into the phytomorphic metaphor by showing flames as parts of beautiful plants. The aim was to show both beauty and horror of wild fires. All the plants shown are made of matches, fume, and flames. The text is as follows: "Report wildfires. Save nature" (see pictures 43-44). In this case, the photo image is used to attract attention, create an aesthetic image and add meaning to the message; all these elements are crucial for the process of perception and decoding of the PSA message.

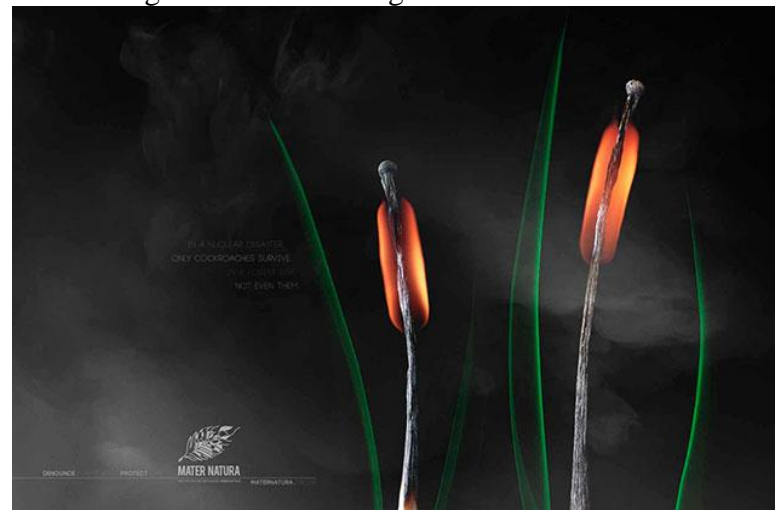

Picture 43 


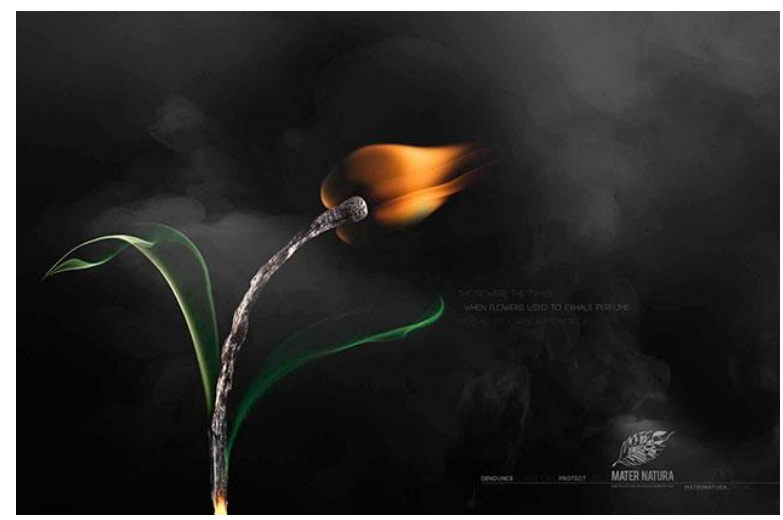

Picture 44

Besides, Russian PSAs often use metaphorical trait transfers that have already lost their creative potential. The example of such kind of the metaphor is the model "Children are flowers" (see pictures 2.4.45-2.4.46).

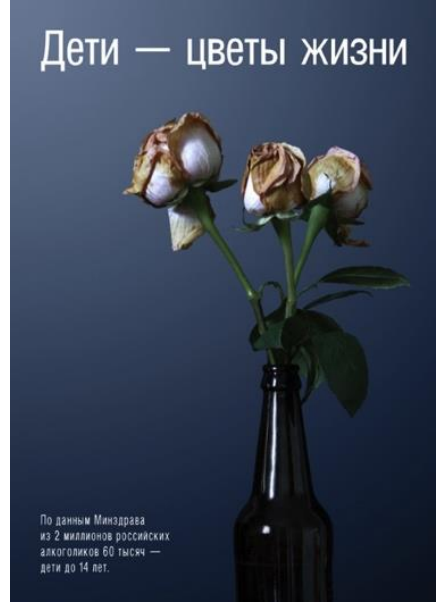

Picture 45

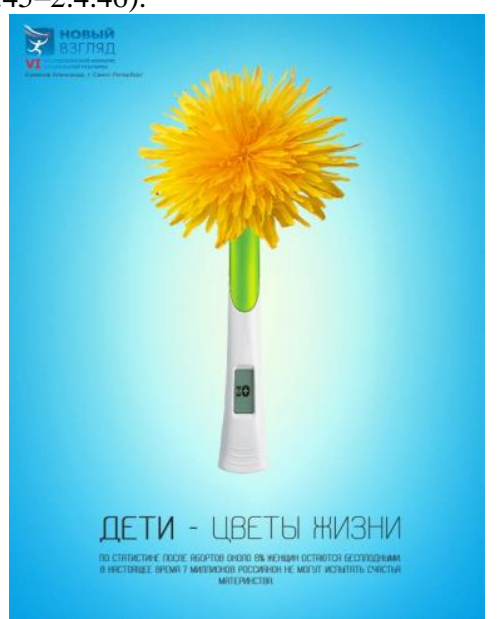

Picture 46

\section{Artifactual Metaphor}

Source domain is a world of artifacts (objects/things).

"Thousands of dogs find themselves in the street, because their masters are tired of playing with them. A dog is not a toy. Remember that" - the authors of the following PSA poster picture the pet as a mechanical toy, thrown away (see pictures 47-48). 


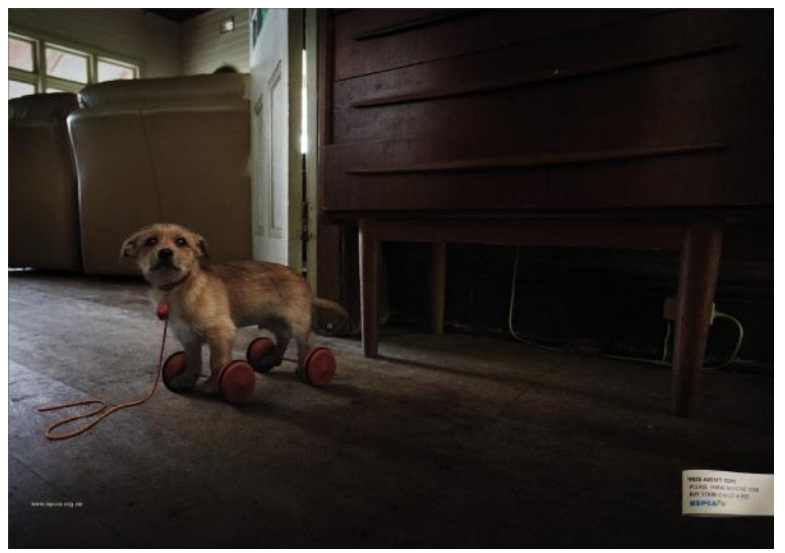

Picture 47

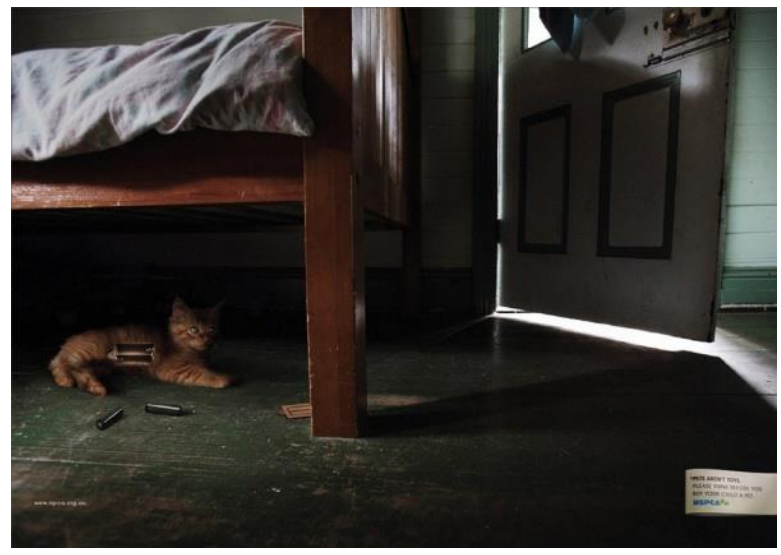

Picture 48

The same metaphor is used in the following PSAs: "An animal is a toy you don't need anymore," "An animal is a junk" (see picture 49).

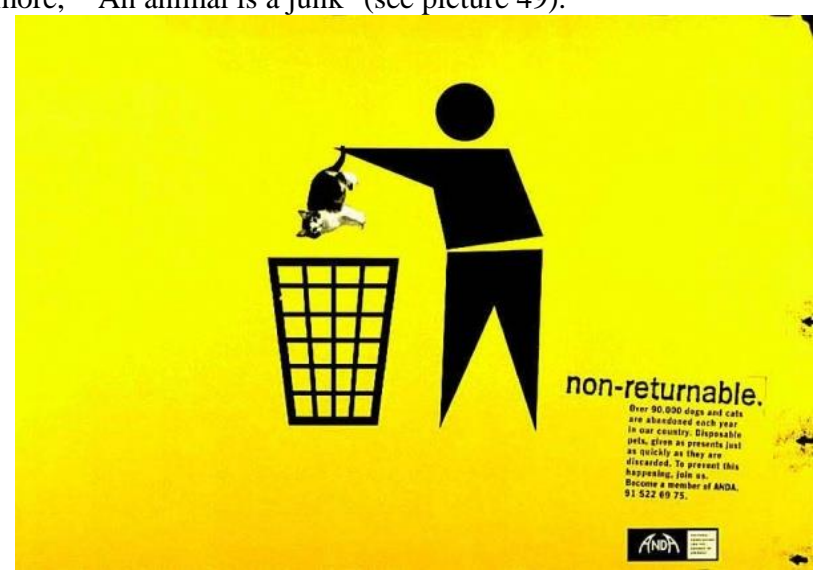

Picture 49 


\section{Conclusions}

The metaphorical models researched are quite standard for PSA discourse, although visualization of metaphorical transfer allows, from the one hand, to present conventional images in new non-stereotypical form; on the other hand, it enhances persuading potential of cognitive metaphor by using non-verbal codes. This polycode nature of PSA text helps to manipulate the process of the message comprehension: non-verbal component usually attracts more attention and has more credibility from the recipient's point of view. The addressee can't consciously follow this non-verbal component, which adds to the manipulative potential of the image used in PSA.

The research is financially supported by the Russian Foundation for Basic Research and Government of the Omsk region, project No. 17-14-55001.

\section{Bibliographic references}

ARUTYUNOVA, N.D. 1999. Language and the human world. Moscow. 896 p. ISBN 5-7859-0027-0.

BARANOV, A.N. 2014. Descriptive theory of metaphor. Moscow. 632 p. ISBN 9785-9905856-7-6.

BARNDEN, J.A. 2010. Metaphor and Metonymy: Making Their Connections More Slippery. In: Cognitive Linguistics. 2010. Vol. 21. Issue 1. pp. 1-34. ISSN 1613-364 BUDAEV, E. 2017. Metaphors of disease in the Russian press. In: XLinguae, European Scientific Language Journal, vol. 10, issue 2, 2017, pp. 30-37. ISSN 13378384. DOI: 10.18355/XL.2017.10.02.03.

CHERNUYAVSKAYA, V.E. 2009. Linguistics of the text: polycode, intertextual, interdiscoursive . Moscow. ISBN. 978-5-397-00289-9.

CHERNYSHEVA, I.V. 2012. Social advertising: textbook for students. Izhevsk. 43 p.

GOOSSENS, L. 1990. Metaphtonymy: The Interaction of Metaphor and Metonymy in Expressions for Linguistic Action. In: Cognitive Linguistics. Vol. 1 (3). pp. 323-340. ISSN 1613-364.

GRISHAEVA, L.I. 2003. Creolized texts are texts of the 21st century? In: Proceedings of Voronezh State University. Series "Linguistics and Intercultural Communication". No 2. pp. 106-108. ISSN 1680-5755.

HAMPL, M. 2012. Metaphor as an element of persuasion in political discourse. In: Kommunikacie. No 1. Pp. 40-43. ISSN 1335-4205.

IVANOVIC, I. 2017. Comparative study of metaphor in British and United States of America (US) political discourse. In: XLinguae, European Scientific Language Journal, vol. 10, issue 2, 2017, pp. 16-29. ISSN 1337-8384. DOI: 10.18355/XL.2017.10.02.02.

KORDA, O.A. 2013. Creolized text in modern printed media: functional characteristics: dis. ... kand. filol. nauk. Yekaterinburg. 227 p.

KUSHNER, A.S. 1991. Apollo in the snow. Leningrad. 512 p. ISBN 5-265-01145-5.

SOROKIN, YU.A. - TARASOV, E.F. 1990. Creolised texts and their communicative function. In: Optimization of linguistic manipulation. Moscow. pp. 180-186. ISBN 502-010983-5.

TERSKIKH, M.V. 2012. Polycode mechanisms of memetaphorization in advertising. In: Vestnik of Pushkin Leningrad State University. 2012. Issue 2. Vol. 7, pp. 162172. ISSN 1818-6653.

TERSKIKH, M.V. - PAVCHUN, M.G. 2014. Specificity of metaphorization in modern advertizing discourse: visual component. In: Linguoculturology. No 8, pp. 164-167. ISBN 978-5-7186-0817-5

VASHUNINA, I.V. 2007. Interaction of visual and verbal components in course of creolized text comprehension. Nizhny Novgorod. 421 p. ISBN 9785852191298. 28.

XLinguae, Volume 11, Issue 2, April 2018, ISSN 1337-8384, eISSN 2453-711X 
VOROSHILOVA, M.B. 2007. Creolized text: research aspects. In: Political Linguistics. No 21. pp. 75-80. ISSN 1999-2629.

WARREN, B. 2006. Referential Metonymy. Scripta Minora, 2003-4. Sweden: Royal Society of Letters at Lund. 95 p. ISBN 91-22-02148-5.

YURIEVA, E.V. Metaphor in slogans. In: Russian Speech. 2015. No 6. pp. 58-62. ISSN 0131-6117.

Words: 6325

Characters: 40974 (22,76 standard pages)

Associate Prof. Marina Viktorovna Terskikh, PhD in Linguistics

Philology and Mediacommunication Department

Dostoevsky Omsk State University

55a Mira prospect

644077 Omsk

Russia

terskihm@mail.ru 